\title{
Um Modêlo Dinâmico de Sistema Político e suas \\ Implicações na Administração Pública
}

\author{
ELIAS MOACY DE OLIVEIRA FREITAS \\ Advogado e Técnico de Administração
}

SUMÁRIO

I - Introdução: A) Uma teoria de análise política. Objetivo e plano do artigo. B) Exemplificação do modêlo. C) Conseqüências metodológicas.

II - Propriedades: A) Sistema de informações: 1. O meio ambiente. 2. Volume e teor das demandas expressas e disposição de suporte dos membros. 3. Condições do sistema e fontes de pressão. 4. Acompanhamento da execução das decisões e ações e de seus efeitos. B) Potencial de respostas: 1. Pressões de demanda. 2. Pressões de suporte. 3. Processo de conversão.

III - Conclusões: A) Quanto às propriedades. B) Quanto às implicações na Administração Pública.

\section{I - INTRODUÇÃO}

artigo

I. A) Uma teoria de análise política. Objetivo e plano do

Vem sendo desenvolvida por David Easton, Professor de Ciência Política da Universidade de Chicago, uma teoria de análise política * que concebe a vida política como um siste-

Velh" EASTON, David, Uma Teoria de Análise Politica, Tradução de Gillberto 
ma de comportamento auto-regulável e autotransformável em harmonia com as finalidades de que é dotado e com sua capacidade de adaptação criadora. O modêlo dinâmico de sistema político formulado já pode ensejar confronto com situações reais.

Contribuir para tal fim, eis o objetivo dêste artigo, ao tentar uma interpretação da teoria sob o ponto de vista prático. Obedecerá, assim, ao seguinte roteiro: exemplificação geral do modêlo reproduzido no Diagrama, levantamento das conseqüências metodológicas, identificação e discussão das propriedades e seu enquadramento nas instituições políticas clássicas e, finalmente, nas conclusões, indicação objetiva das novas idéias e de seus possíveis reflexos na Administração Pública.

\section{B) Exemplificação do modêlo}

Suponha-se que, entre as camadas sociais interessadas (meio ambiente intra-social), se articule reação contra eventuais distorções de certo plano instituído pelo Govêrno e em execução através da Administração Pública, a qual, inclusive, é uma das instituições políticas, conforme a classificação da UNESCO.

O sistema político, que, por meio de um esquema de informações e de diagnósticos, tem conhecimento prévio das mudanças sociais relevantes para a sua ação, mais precisamente, dos acontecimentos ou distúrbios internos ou externos capazes de envolver o processo decisório, poderá agir antecipadamente, modificando as condições geradoras de reação daquela natureza, a qual, assim, não terá curso, graças à previdente resposta.

Caso não proceda dêsse modo, a reação transformar-se-á em pressão (input) de demanda e de suporte. Pressão de demanda política, porque já assume a forma de proposta para que alguma decisão seja tomada pelo Govêrno (Autoridades); pressão de suporte, porque ameaça abalar os sentimentos de sustentação do regime e de confiança em seus meios de ação.

A pressão de demanda resultante responderá agora o sistema de várias maneiras, até convertê-la de uma forma ou de outra, através de suas estruturas e processos (linha sinuosa), em decisões ou ações reguladoras (outputs). Tais atos, com a execução, retroagem sôbre o meio ambiente, modificam-no, regulam as pressões e suas fontes e influenciam a próxima série de efeitos. Todo o complexo de interações forma um círculo de regulagem retroativa (circuito de feedback), que flui até 
as Autoridades (linhas interrompidas nos retângulos do meio ambiente e do sistema).

Mas, se nenhuma ação sobrevier, a pressão aumentará sôbre o sistema, em têrmos de demandas mais clamorosas e de maior declínio do nível de suporte, podendo mesmo, tal seja a tensão social, a acumulação e o caldeamento com outras pressões oriundas dos diferentes sistemas do meio ambiente, chegar ao ponto de esvaziá-lo ou destruí-lo. Nesta hipótese, não estaria o sistema mais em condições de manter o statu quo e, especialmente, o processo de conversão das pressões em atos decisórios.

Para vencer semelhante crise, teria então de mudar de tipo (democrático, autoritário, totalitário), tantas vêzes quanto possível, alterando o modo de funcionamento de suas funções vitais, chamadas de variáveis essenciais, a saber: a) tomada e execução de decisões; e b) aceitação dessas decisões e ações como autoritárias, a maior parte do tempo, pela maioria das pessoas da sociedade.

Se a mudança de tipo ainda não resolver o impasse, o que em regra, julga-se suficiente, estaria, afinal, em perigo a persistência mesma do sistema, qualquer que fôsse o seu tipo, expondo-se ao risco de fracionar-se em várias unidades independentes (movimentos separatistas) ou de ser absorvido por outra sociedade sujeita a diverso sistema político, como se verifica històricamente.

I. C) Conseqüências metodológicas

Vê-se, pelo exemplo, que é através da combinação das propriedades feedback e resposta que o sistema se torna apto a regular as pressões, modificando as condições do meio ambiente ou mudando a direção de seu próprio comportamento, em defesa das variáveis essenciais.

A propriedade feedback, que se identifica como as informações sôbre todo o circuito retroativo, favorece a aplicação do princípio da previsão e implica a existência de um sistema de informações precisas sôbre os seguintes pontos: condições do meio ambiente; volume e teor das demandas expressas; disposição de suporte do regime por parte dos membros; estado do sistema e suas pressões internas; e execução das decisões e ações e seus efeitos.

Considera-se valiosa a função dos Bancos de Dados ou de memória na manipulação do sistema de informações. E aqui vem a primeira implicação das novas idéias no Serviço Público: a instituição de um Banco de Dados, a nível central, interligado 
a terminais eletrônicos, a níveis periféricos, constituiria um importante passo no aperfeiçoamento do processo decisório. Em área setorial, aliás, é justo assinalar os esforços desenvolvidos pelo atual Departamento Administrativo do Pessoal Civil (DASP), ao munir-se de um "Centro de Documentação e Informática", com armazenamento de informações essenciais às decisões inerentes à política de pessoal.

Quanto à outra propriedade - resposta - devem acompanhar vários tipos de regularização das pressões, assim de demandas como de suporte. Indicam-se como principais tipos de respostas às pressões de demandas: ação dos reguladores estruturais (partidos políticos, grupos de interêsse, líderes de opinião ou comunicação de massa), os quais tendem a limitar o número de demandas, antes de submetidas ao Govêrno; coerções culturais (critérios de exclusão de resoluções políticas); síntese e homogeneização (programa); e aumento de canais.

As pressões de suporte, por seu turno, reclamam êstes tipos de respostas: regularização estrutural (nova ordem constitucional); doutrina política; e decisões como mecanismos reguladores. O potencial de respostas, finalmente, culmina com o processo de conversão das pressões de demandas e de suporte (inputs) em decisões e ações coercitivas (outputs), onde tem relêvo o processo legislativo.

A contribuição da Administração Pública, também nas relações dinâmicas do potencial de respostas, é decisiva, porquanto, sem aplicação inclusive dos princípios de planejamento, coordenação, descentralização e contrôle, entre outras concepções modernas de organização e métodos, não poderá funcionar racionalmente o sistema político. Ver-se-á, a seguir, em rápidos lances, o desdobramento das propriedades acima aludidas, com suas implicações mais iminentes no Serviço Público.

\section{II - PROPRIEDADES}

\section{A) Sistema de Informações}

1. O meio ambiente

O meio ambiente está esquemàticamente representado nos retângulos do Diagrama, devendo entender-se que os sistemas sociais abrangem, lògicamente, os subsistemas cultural, demográfico, econômico e de estrutura social. As mudanças, ou relações mútuas, que ocorrem nos sistemas ali indicados, bem como as transações, ou trocas, entre êles e o sistema político, são ilimitadas e complexas, de tal modo que é impossível e inoperante examinar cada uma de per si, como fôra em vão tentado pela "Análise Funcional", já superada. 
A tarefa, porém, está hoje simplificada, porque se verificou que o impacto do meio ambiente no sistema político apenas se reflete em duas variáveis sumárias: inputs de demandas e de suporte. Os inputs (pressões) são os indicadoreschaves da maneira pela qual acontecimentos e condições do meio ambiente modificam e afetam o funcionamento do sistema político. Canalizam-se nêles tôdas as múltiplas transações acima aludidas, suscetíveis de implicar ação política.

Mais claramente: as mudanças no meio ambiente repercutem no sistema político de duas maneiras: a) ora sob a forma de solicitações, manifestações ou mensagens, em volume e variedades notáveis, reivindicando programas e decisões que dependam da ação política (pressões de demandas); b) ora sob a forma de distúrbios, ou acontecimentos, em prol de nôvo conjunto de estruturas, nova ordem constitucional e novas autoridades políticas que forneçam liderança e capacidade administrativa (pressões de suporte).

É escusado realçar a necessidade de um sistema de informações sôbre o meio ambiente, abrangendo as mudanças da forma a, da forma $\mathbf{b}$, ou de ambas, alternada ou conjuntamente, mas voltado de modo especial ao processo decisório, a fim de que êste exprima a realidade social. A existência de racional organização administrativa, com o estabelecimento de canais apropriados, faz-se sentir flagrantemente nesse contexto.

II.A.2 Volume e teor das demandas expressas e disposi̧̧ão de suporte dos membros

As informações supra, por preciosas que sejam, não visam especificamente às demandas formalizadas, mas, sobretudo, às transmitidas pelos meios de comunicação de massa ou inferidas de diagnósticos técnicos, as quais carecem de forma e conteúdos próprios para uma decisão ou ação política, em condições operacionais correntes.

As demandas, entretanto, prosseguem em seu curso, até serem incorporadas, de uma forma ou de outra, pelos membros do sistema, ou sejam, pelas pessoas que estão em papéis politicos, mais ou menos diretamente relacionadas às decisões autoritárias e que as podem formalizar em anteprojetos de atos oficiais, quer na área do Legislativo, quer na área do Executivo.

Identificam-se, na prática, como as pessoas a quem cabe a iniciativa das leis ou que as aprovem, sancionem ou promul- 
guem, ao nivel municipal, estadual ou federal. São estas, de modo geral, as pessoas de fato qualificadas como membros do sistema político, entre as quais se destacam as Autoridades. 0 membro é a unidade estrutural básica de análise do sistema, sendo importantes, assim, as informações sôbre o volume e teor das demandas formalizadas.

E não apenas sôbre as demandas expressas, julgam-se igualmente essenciais informações sôbre a disposição de suporte dos membros. Se estão aquiescentes com o sistema e realmente solidários com a comunidade política ou, ao contrário, na iminência de revolta ou mesmo insatisfeitos. Note-se que a informação pode ser usada, conforme as circunstâncias, para enfraquecer ou fortificar os sentimentos de sustentação do regime ou de alguns de seus aspectos importantes.

\section{II.A.3. Estado do sistema e fontes de pressão}

As principais fontes de pressão são, em geral, de duas naturezas: falência de outputs (decisões e ações) e sobrecarga de input de demanda. Ocorre o primeiro caso quando as Autoridades se manifestam incapazes ou não desejosas de atender às demandas dos mesmos em proporções determináveis, pelo menos as dos membros politicamente fortes (admite-se ser a causa fundamental dos movimentos de secessão). O segundo quando, por falta de canais ou demora no processamento, as demandas multiplicam-se em número e variedades excessivos, gerando-se acumulação.

Em ambas as hipóteses, surgem conseqüências para 0 input de suporte, o qual declina, e apresenta, por sua vez, outras pressões, cujo índice principal se situa na ordem constitucional, em alguns tipos de autoridades para o regime ou certos aspectos do sistema. Convém aduzir, ainda, a existência de pressões dentro do sistema (ou withinput, neologismo lançado pelo autor da teoria).

As respostas a tais tipos de pressão serão indicadas nos tópicos pertinentes. Por enquanto o que se deseja revelar é a necessidade de informações sôbre êsses problemas, as quais habilitam os membros do sistema a tomarem decisões antecipadas e eficazes.

II.A.4. Acompanhamento da execução das decisões e ações e seus efeitos.

O último tipo de informações concerne ao acompanhamento da execução dos outputs e de seus efeitos, o que toca, aliás, diretamente às funções vitais do sistema político, já refe- 
ridas, isto é, tomada e execução de decisões e ações autoritárias e aceitação dessas decisões, a maior parte do tempo, pela maioria da sociedade.

Trata-se de ponto visceralmente ligado à Administração Pública, já que, entre outros, envolve os princípios de planejamento e contrôle. Êste, no que tange à execução dos programas e decisões; e aquêle, porque lhe é imanente a organização de um esquema de acompanhamento da execução dêsses programas e decisões, em caráter global e setorial.

Os relatórios dos diversos órgãos, em geral exaustivos e propagandísticos, não se prestam bem ao acompanhamento da execução. As técnicas de "administração por exceções", apontando apenas os desvios das normas, padrões de desempenho e objetivos inerentes ao sistema de valôres estabelecidos, tornam-se aí recomendáveis, inclusive pelas crescentes exigências de informática.

Com êste dado, fica concluída a avaliação sumária da teoria quanto às informações que retornam às autoridades através de todo o circuito retroativo, chamado circuito de feedback, informações cuja disponibilidade é considerada vital ao comportamento do sistema, porque faculta, antes de tudo, respostas adequadas às pressões que fluem incessantemente.

E que o sistema de informações permite, em suma, criar condições para a ação antecipada nos seguintes pontos básicos: regularização do volume de demandas ou ampliação do suporte, conforme a previsão de pressões; auto-regulagem ou autotransformação do regime em harmonia com novos objetivos e novas finalidades; e relacionamento de alguma forma causal ao que ocorrera prèviamente, do comportamento do sistema. Seguem-se, agora, os tipos de respostas, dentro da orientação aludida no tópico I.C.

II.B. Potencial de respostas

\section{Pressões de demanda}

Registram-se os seguintes tipos de respostas às pressões de demanda: os reguladores estruturais, a coerção cultural, o programa e o aumento de canais. Os reguladores estruturais, compreendendo partidos políticos, grupos de interêsse (associações de classe em geral), líderes de opinião ou a comuniCação de massa (sobretudo quando utilizados os meios frios de maior poder de mensagem), deverão atuar na fase em que as demandas, antes de formalizadas, começam a definir-se em propostas para decisão e ação política. Êles estão, por isso, 
estratègicamente situados na entrada dos canais de admissão ao sistema, e correspondem, na classificação da UNESCO, à vida política. O número e a variedade de demandas dependem, sem dúvida, das características dêsses guardiães do sistema.

As coerções culturais também controlam as demandas. Existentes de uma forma ou de outra em todo sistema, são as inibições culturais em relação à natureza das necessidades que um membro possa achar apropriadas a uma decisão politica. Assuntos estéticos, religiosos, por exemplo, é possível que sejam considerados motivo de preocupação apenas dos respectivos sistemas do meio ambiente. Essas coerções ajudam a limitar também o número de demandas no seu próprio início, à medida que começam a caracterizar-se ainda como necessidades, aspirações ou desejos não-políticos.

O programa, como sintese de demandas, é função cumprida, em regra, pelos reguladores estruturais, especialmente partidos políticos e grupos de interêsse. As técnicas de planejamento poderão ser amplamente empregadas na racionalização das demandas em qualquer nível e de qualquer natureza, eis que tôdas exigem planejamento e, se dependentes de decisão política, convertem-se em demandas políticas. Do ponto-devista do processo decisório, assume o planejamento caráter integral.

O aumento de canais seria, finalmente, o último tipo comum de regularização de demandas. Admite-se que os canais de ad́missão ao sistema político se estendem até as Autoridades produtoras de outputs em todos os níveis (federal, estadual e municipal) e em tôdas as competências (legislativa, executiva e judiciária). Qualquer órgão nas estruturas dêsses Podêres, em regime democrático, pode, é claro, receber uma demanda, regulá-la se tem atribuições sôbre o respectivo objeto ou, afinal, encaminhá-la para o processamento formalizado, em consonância com a ordem constitucional.

Pela avaliação empreendida, verifica-se que os tipos usuais de respostas aos inputs de demandas (reguladores estruturais, coerção cultural, programa sintético comum e aumento de canais) atuam sempre no sentido de racionalizá-las, quer limitando-Ihes o número e a variedade, quer processando-as logo se há meios, quer formalizando-as para a conversão em decisões políticas, quer, finalmente, compatibilizando-as com a ordem constitucional. As óbvias implicações nas instituições políticas e administrativas podem ser tècnicamente resumidas na aplicação sistemática dos princípios de organização, plane- 
jamento, coordenação e descentralização. Veja-se, na ordem da análise, o elenco de respostas aos inputs de suporte.

II.B.2. Pressões de suporte

As demandas, como se tem visto (especialmente no tópico II.A.1), representam apenas um índice de identificação e localização da forma pela qual os distúrbios internos e do meio ambiente podem pressionar o sistema político. O segundo índice reflete-se no suporte. Elo de ligação entre o meio ambiente e o sistema, admite-se ser necessário suporte para os vários aspectos do sistema, para certos tipos de autoridades e para a própria comunidade política. O suporte não deve cair abaixo de um índice mínimo. Donde as respostas convenientes e graduadas às situações emergentes, a saber: regularização estrutural, suporte difuso (doutrina) e as próprias decisões políticas utilizadas como mecanismos reguladores.

A regularização estrutural consiste na implantação de nova ordem constitucional, reformulando-se, por conseguinte, as estruturas, normas e objetivos do regime. É a estratégia mais radical, pois implica numa autotransformação. Tem sido utilizada quando o sistema corre o risco de desorganização tal que as variáveis essenciais não podem mais funcionar. Previne, dêsse modo, o caos, garantindo a persistência do sistema (v.I.B. in fine), ou seja, a continuidade do processo decisório.

O suporte difuso consiste no estímulo, sobretudo aos membros jovens, de sentimentos de legitimidade, de submissão ao sistema independente de momentâneas frustrações de desejos particulares, de bem-estar comum acima de interêsses individuais ou grupais e de comunidade política. Essa forma de fortalecimento dos laços entre os membros e o sistema recorre a certos métodos de socialização, como a doutrina política, onde a ideologia desempenha relevante papel. A doutrina (de docere = ensinar), que indique os caminhos a seguir, que fixe regras de ação e proponha objetivos futuros, valendo-se, é lógico, de juízos de valor e da ideais de reformas extrapoliticos (filosóficos e ideológicos).

Os outputs constituem o último tipo de resposta a um declínio de suporte. É certo que os membros do sistema sustentalo-ão acima de tudo em razão da lealdade doutrinária e de suas convicções políticas. Mas, vimos nos tópicos II.A.2. e 3 ., que pelo menos algumas de suas mais justas demandas deverão ser satisfeitas. As decisões com essa motivação especial estimulam o que se chama de suporte específico: reflexo da satisfação dos membros ao perceberem que suas demandas estão 
sendo atendidas. A frustração sistemática de pretensões consideradas justas, reciprocamente, desgasta o suporte específico, reclamando compensação com o refôrço do suporte difuso. Êstes dois tipos de respostas compensam-se, pois, mùtuamente.

As demandas regionais (Federação) e outras de igual importância não podem, adverte a teoria, ser olvidadas ou postergadas constantemente, e sim integradas no processo geral de tomada e execução de decisões e ações. Movimentos separatistas, já o foi lembrado, têm surgido principalmente em virtude do desapreço a êsse tipo de resposta às pressões de suporte. Os outputs, no entanto, apresentam conseqüências mais vastas, porquanto modificam o meio ambiente, o próprio sistema, regulam as demandas e alimentam ou destroem os sentimentos de suporte do regime. Constituem, afinal, uma das variáveis essenciais do sistema político.

\section{II.B.3. O processo de conversão}

As pressões, quer de demandas, quer de suporte, que escapam às variadas formas de respostas regularizadoras acima indicadas, exigem, enfim, um processo de conversão, o qual abrange (entende-se) as atribuições constitucionais prescritas às autoridades, a iniciativa das leis e, em suma, o processo legislativo, de onde promanam verdadeiramente as decisões e ações coercitivas para tôda a sociedade. O processo de conversão, assim identificado, é que responde pròpriamente pela persistência do sistema político, qualquer que seja o seu tipo, pois é o que the assegura a aptidão de manter em funcionamento as variáveis essenciais.

Um vasto processo de conversão poderia ser assim descrito: a) seleção de algumas, entre a variedade de demandas existentes, como os objetivos e finalidades do sistema; b) comprometimento dos recursos limitados da sociedade para a realização dessas demandas; c) obtenção dos recursos de ordem material através de outputs, que assumem a forma de ordem, taxação ou expropriação; e d) organização e mobilização dos recursos humanos para garantir o suporte ao sistema, como um todo, ou para as Autorídades específicas. Vê-se, assim, que o processo de conversão final das demandas em decisões e ações deve estar conjugado com o sistema de informações e os outros tipos de respostas, onde decisiva se torna a autação da Administração Pública, particularmente através da aplicação dos princípios de planejamento, coordenação, descentralização e contrôle. 


\section{III - CONCLUSÕES}

Segundo a interpretação oferecida, implica a teoria conclusões talvez significativas para a Ciência Política, encarada como uma das ciências do comportamento e dentro da nova forma de abordagem caracterizada pela análise de sistemas. A orientação pragmatista de início aludida, entretanto, restringe estas conclusões a apenas alguns aspectos de seu quadro conceptual e às implicações mais flagrantes na Administração Pública. Por isso, limitar-se-á a um sumário sôbre ambos os pontos.

\section{A) Quanto às propriedades:}

1. o sistema de informações implica a produção de dados e diagnósticos exatos sôbre os sistemas do meio ambiente, inclusive internacionais, em têrmos de captação de mudanças suscetíveis de afetar o sistema político; o volume e teor das demandas expressas e disposição de suporte dos membros; e as condições do sistema e das fontes potenciais de pressão, internas e externas;

2. o potencial de respostas, por seu turno, exige: a) do lado das demandas: ação dos reguladores estruturais, situados à entrada dos canais de admissão ao sistema, limitativa do número e variedade das demandas que fluem do meio ambiente para o sistema; utilização de programas sintéticos comuns; e eficiência dos canais de admissão ao sistema, capazes de processar as demandas que não impliquem necessàriamente ação política; b) do lado do suporte: elaboração ou consolidação de doutrina política; aptidão dos instrumentos de regularização estrutural; e utilização dos outputs como mecanismos reguladores do declínio de suporte;

3. o processo de conversão, finalmente, reclama eficiência do processo legislativo e coordenação com o sistema de informação e os demais tipos de respostas, sendo certo que as propriedades feedback e respostas devem estar sempre conjugadas.

B) Quanto às implicações na Administração Pública, além de destacadas a cada passo no curso dêste trabalho, podem ainda merecer referência:

1. aplicação generalizada, no sentido horizontal e vertical, dos princípios de planejamento, coordenação, descentralização e contrôle;

2. manutenção de um esquema de acompanhamento das decisões e ações e de seus efeitos; 
3. instituição de um Banco de Dados, a nível central, com terminais eletrônicos, a níveis periféricos; ções";

4. introdução das técnicas de "administração por exce-

5. delegação de competência aos canais de admissão ao sistema;

6. amplo programa de treinamento de pessoal em organização e métodos, informática e análise de sistemas, entre outras especializações indispensáveis à evolução científica e tecnológica; e, em suma,

7. organização de recursos físicos e humanos em função do adivento da automação no Serviço Público. 


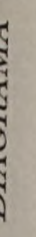


